Supplement of Solid Earth, 11, 2257-2281, 2020

https://doi.org/10.5194/se-11-2257-2020-supplement

(c) Author(s) 2020. This work is distributed under

the Creative Commons Attribution 4.0 License.

(c) (i)

Supplement of

\title{
Influence of basement rocks on fluid evolution during multiphase deformation: the example of the Estamariu thrust in the Pyrenean Axial Zone
}

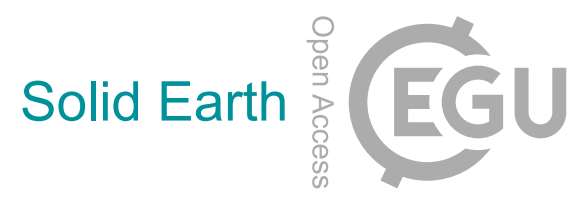

Daniel Muñoz-López et al.

Correspondence to: Daniel Muñoz-López (munoz-lopez@ub.edu)

The copyright of individual parts of the supplement might differ from the CC BY 4.0 License. 


\section{Methods}

This study integrates a field compilation of structural data and samples as well as petrological and geochemical analyses of calcite cements and related host rocks. The structural data includes the orientation of bedding, foliations, and fractures in addition to crosscutting relationships and kinematics. Such data were plotted in equal-area lower-hemisphere projections and different fracture sets were stablished according to their type, strike, mineral infillings, and relative age deduced from crosscutting relationships. All these data were integrated in a schematic map and a cross-section of the Estamariu thrust and the Cerc basin (Fig. 2A, B and 3). Samples considered representative of the involved host rocks and all calcite vein generations observed in the different fracture sets and fault-related structures were selected for petrological and geochemical analyses. Thin sections of these samples were prepared and studied under a Zeiss Axiophot optical microscope and a Cold cathodoluminescence (CL) microscope model 8200 Mk5-1 operating between 16-19 kV and $350 \mu \mathrm{A}$ gun current.

Thirty-five representative samples of the different generations of calcite cements and the carbonate portion of the Devonian rocks were sampled for stable isotope analysis. Sampling was carried out with a $500 \mu \mathrm{m}$-diameter microdrill. 50-100 $\mu \mathrm{g}$ of powdered samples were reacted with 100\% phosphoric acid during two minutes at 70 ${ }^{\circ} \mathrm{C}$. The resultant $\mathrm{CO}_{2}$ was analyzed with an automated Kiel Carbonate Device attached to a Thermal Ionization Mass Spectrometer Thermo Electron MAT-252 (Thermo Fisher Scientific) according to the method of (McCrea, 1950). For calibration, the International Standard NBS-18 and the internal standard RC-1, traceable to the International Standard NBS-19, were used. The standard deviation is $\pm 0.03 \%$ or $\delta^{13} \mathrm{C}$ and $\pm 0.05 \%$ o for $\delta^{18} \mathrm{O}$ expressed with respect to the VPDB standard (Vienna Pee Dee Belemnite).

The elemental composition of twelve samples of calcite cements and related host rocks were analyzed using a high resolution inductively coupled plasma-mass spectrometry (HR-ICP-MS, model Element XR, Thermo Fisher Scientific). $100 \mathrm{mg}$ of powdered samples were dried at $40{ }^{\circ} \mathrm{C}$ during $24 \mathrm{~h}$ and then they were acid digested in closed polytetrafluoroethylene (PTFE) vessels with a combination of $\mathrm{HNO}_{3}+\mathrm{HF}+\mathrm{HClO}_{4}(2.5 \mathrm{~mL}$ : $5 \mathrm{~mL}$ : $2.5 \mathrm{~mL} \mathrm{v} / \mathrm{v}$ ). The samples were evaporated and $1 \mathrm{~mL}$ of $\mathrm{HNO}_{3}$ was added to make a double evaporation. Finally, the samples were re-dissolved and diluted with MilliQ water $\left(18.2 \mathrm{M} \Omega \mathrm{cm}^{-1}\right)$ and $1 \mathrm{~mL}$ of $\mathrm{HNO}_{3}$ in a $100 \mathrm{~mL}$ volume flask. A tuning solution containing $1 \mathrm{~g} \mathrm{~L}^{-1} \mathrm{Li}, \mathrm{B}, \mathrm{Na}, \mathrm{K}, \mathrm{Sc}, \mathrm{Fe}, \mathrm{Co}, \mathrm{Cu}, \mathrm{Ga}, \mathrm{Y}, \mathrm{Rh}, \mathrm{In}, \mathrm{Ba}, \mathrm{Tl}$, U was used in order to improve the sensitivity of the ICP-MS , and as internal standard, $20 \mathrm{mg} \mathrm{L}^{-1}$ of a monoelemental solution of ${ }^{115}$ In. Reference materials are the BCS-CRM n 393 (ECRM 752-1) limestone, JA-2 Andesite and JB-3 Basalt. The precision of the results was expressed in terms of two standard deviations of a set of eight reference materials measurements (reference material JA-2), whereas accuracy (\%) was calculated using the absolute value of the difference between the measured values obtained during the analysis and the certified values of a set of eight reference material analysis (reference material BCS-CRM $n^{\circ} 393$ for major oxides and JA-2 for trace elements). The detection limit (DL) was calculated as three times the standard deviation of the average of ten blanks. 
The ${ }^{87} \mathrm{Sr} /{ }^{86} \mathrm{Sr}$ ratio was analyzed for eight representative samples of calcite cements and host rocks. Powdered samples were dissolved in $5 \mathrm{~mL}$ of $10 \%$ acetic acid. After centrifugation, the supernatant was dried and dissolved in $1 \mathrm{~mL}$ of $1 \mathrm{M} \mathrm{HNO}_{3}$. The solid residue generated after evaporation was diluted in $3 \mathrm{~mL}$ of $3 \mathrm{M} \mathrm{HNO}_{3}$ and loaded into chromatographic columns to separate the Rb-free Sr fraction, using SrResinTM (crown-ether (4,4'(5')-di-t-butylcyclohexano-18-crown-6)) and 0.05M $\mathrm{HNO}_{3}$ as eluent. After evaporation, samples were loaded onto a Re filament along with $1 \mu \mathrm{L}$ of $1 \mathrm{M}$ phosphoric acid and $2 \mu \mathrm{L}$ of $\mathrm{Ta}_{2} \mathrm{O}_{5}$. Isotopic analyses were carried out in a TIMS-Phoenix mass spectrometer performing a dynamic multicollection method, during 10 blocks of 16 cycles each one keeping a ${ }^{88} \mathrm{Sr}$ beam intensity of 3 -V. Possible ${ }^{87} \mathrm{Rb}$ interferences and possible mass fractionation during sample loading and analysis were corrected and normalized with the reference value of ${ }^{88} \mathrm{Sr} /{ }^{86} \mathrm{Sr}=0.1194$. The isotopic standard NBS-987 was analyzed six times during sample analysis, yielding an average value of $0.710243 \pm 0.000009$ (standard deviation, 2 $\sigma$ ). NBS 987 data have been used to correct the sample ratios for standard drift from the certified value. The analytical error in the ${ }^{87} \mathrm{Sr} /{ }^{86} \mathrm{Sr}$ ratio, referred to two standard deviations, was $0.01 \%$, whereas the internal precision is 0.000003 . Sr procedural blanks were always below $0.5 \mathrm{ng}$.

The ${ }^{143} \mathrm{Nd} /{ }^{144} \mathrm{Nd}$ ratios were analyzed in seven samples of calcite cements and host rocks. Samples were weighted in Teflon ${ }^{\circledR}$ vessels, with enriched spike solution $\left({ }^{149} \mathrm{Sm}-{ }^{150} \mathrm{Nd}\right.$ - Oak Ridge) and dissolved in $5 \mathrm{~mL}$ of ultrapure $\mathrm{HF}$ and $3 \mathrm{~mL}$ of ultrapure $\mathrm{HNO}_{3}$ (Merck-Suprapur ${ }^{\mathrm{TM}}$ ). The PFA-vessels were placed 65 hours at 120 ${ }^{\circ} \mathrm{C}$ into an oven. After that, cold vials were evaporated at $120^{\circ} \mathrm{C}$ on a heat plate. $4 \mathrm{~mL}$ of $6 \mathrm{~N}$ distilled HCL were added to the dried samples and placed at $120{ }^{\circ} \mathrm{C}$ in an oven overnight. The solid residue generated after evaporation was dissolved in $3 \mathrm{~mL}$ of distilled and titrated $2.5 \mathrm{~N} \mathrm{HCl}$. Samples were centrifuged at $4000 \mathrm{rpm}$ for 10 minutes to separate the possible dissolved fraction from the residue. Chromatographic separation of the whole group of REE was performed with a previously calibrated cation exchange resin DOWEX 50W-X8 200400 mesh. After that, recovered REE fractions were dried and again dissolved in $200 \mu \mathrm{L} \mathrm{HCl} 0.18 \mathrm{~N}$. Such solutions were passed in a new chromatographic step (Ln-resin). The result is a complete separation between the $\mathrm{Nd}$ and the $\mathrm{Sm}$ fractions, using $0.3 \mathrm{~N} \mathrm{HCl}$ and $0.4 \mathrm{~N} \mathrm{HCl}$ as eluent, respectively. Dried Sm and $\mathrm{Nd}$ samples dissolved with $2 \mu \mathrm{L}$ of $0.05 \mathrm{M}$ phosphoric acid were loaded onto a side Rhenium (Re) filament of a triple $\mathrm{Re}$ filament arrangement. Nd ratios were analysed in a mass spectrometer TIMS-Phoenix ${ }^{\circledR}$, using a dynamic multicollection method, through 160 cycles at a stable intensity of $1 \mathrm{~V}$ for the ${ }^{144} \mathrm{Nd}$ mass. In turn, Sm ratios were analysed in the same spectrometer, using a single static method through 112 cycles keeping $1 \mathrm{~V}$ intensity for the ${ }^{149} \mathrm{Sm}$ mass. Nd analyses were corrected for ${ }^{142} \mathrm{Ce}$ and ${ }^{144} \mathrm{Sm}$ interferences, if any, and normalized to a ratio of ${ }^{146} \mathrm{Nd} /{ }^{144} \mathrm{Nd}=0.7219$ to correct the possible mass fractionation during the processes of loading and analysing at the TIMS. Nd isotopic standard JNdi-1 was checked to correct the sample ratios for standard drift from the certified value. The analytical error (2STD) was $0.1 \%$ in the ${ }^{147} \mathrm{Sm} /{ }^{144} \mathrm{Nd}$ ratio and $0.006 \%$ in the ${ }^{143} \mathrm{Nd} /{ }^{144} \mathrm{Nd}$ ratio. Procedural blanks were always below $0.1 \mathrm{ng}$.

Clumped isotope thermometry of the calcite cements was carried out in order to determine the temperature and composition ( $\delta^{18} \mathrm{O}_{\text {fluid }}$ ) of the vein-forming fluids. $2-3 \mathrm{mg}$ aliquots from cements were measured with an automated line, the Imperial Batch Extraction system (IBEX), developed at Imperial College. Samples were 
dropped in $105 \%$ phosphoric acid at $90{ }^{\circ} \mathrm{C}$ and reacted during $30 \mathrm{~min}$. The reactant $\mathrm{CO}_{2}$ was separated with a poropak-Q column and transferred into the bellows of a Thermo Scientific MAT 253 mass spectrometer. The characterization of a replicate consisted of 8 acquisitions in dual inlet mode with 7 cycles per acquisition. The post-acquisition processing was completed with Easotope, a software for clumped isotope analyses (John and Bowen, 2016). During phosphoric acid digestion, $\Delta_{47}$ values were corrected for isotope fractionation using a phosphoric acid correction of $0.069 \%$ at $90{ }^{\circ} \mathrm{C}$ for calcite (Guo et al., 2009). The data were also corrected for non-linearity applying the heated gas method (Huntington et al., 2009) and projected into the reference frame of (Dennis et al., 2011). Carbonate $\delta^{18} \mathrm{O}$ values were calculated with the acid fractionation factors of (Kim and O’Neil, 1997). Results were converted to temperatures applying the calibration method of (Kluge et al., 2015). Calculated $\delta^{18} \mathrm{O}_{\text {fluid }}$ values are expressed in \%o with respect to the Vienna Standard Mean Ocean Water (VSMOW).

\section{References of methods}

Dennis, K. J., Affek, H. P., Passey, B. H., Schrag, D. P. and Eiler, J. M.: Defining an absolute reference frame for 'clumped' isotope studies of CO2, Geochim. Cosmochim. Acta, 75(22), 7117-7131, doi:10.1016/j.gca.2011.09.025, 2011.

Guo, W., Mosenfelder, J. L., Goddard, W. A. and Eiler, J. M.: Isotopic fractionations associated with phosphoric acid digestion of carbonate minerals: Insights from first-principles theoretical modeling and clumped isotope measurements, Geochim. Cosmochim. Acta, 73(24), 7203-7225, doi:10.1016/j.gca.2009.05.071, 2009.

Huntington, K. W., Eiler, J. M., Affek, H. P., Guo, W., Bonifacie, M., Yeung, L. Y., Thiagarajan, N., Passey, B., Tripati, A., Daëron, M. and Came, R.: Methods and limitations of "clumped" CO2isotope $(\Delta 47)$ analysis by gas-source isotope ratiomass spectrometry, J. Mass Spectrom., 44(9), 1318-1329, doi:10.1002/jms.1614, 2009.

John, C. M. and Bowen, D.: Community software for challenging isotope analysis: First applications of 'Easotope' to clumped isotopes, Rapid Commun. Mass Spectrom., 30(21), 2285-2300, doi:10.1002/rcm.7720, 2016.

Kim, S.-T. and O’Neil, J. R.: Equilibrium and nonequilibrium oxygen isotope effects in synthetic carbonates, Geochim. Cosmochim. Acta, 61(16), 3461-3475, doi:10.1016/S0016-7037(97)00169-5, 1997.

Kluge, T., John, C. M., Jourdan, A.-L., Davis, S. and Crawshaw, J.: Laboratory calibration of the calcium carbonate clumped isotope thermometer in the $25-250{ }^{\circ} \mathrm{C}$ temperature range, Geochim. Cosmochim. Acta, 157, 213-227, doi:10.1016/j.gca.2015.02.028, 2015.

McCrea, J. M.: On the isotopic chemistry of carbonates and a paleotemperature scale, J. Chem. Phys., doi:10.1063/1.1747785, 1950. 
